\title{
On the Origin of Early Jade Dagger-Axe: A Brief Analysis
}

\author{
Cheng Xue1, Yingzhi Xu${ }^{2}$ \\ ${ }^{1}$ School of Cultural Heritage, Northwest University, Xi'an, China \\ ${ }^{2}$ School of Sociology and Political Science, Shanghai University, Shanghai, China \\ Email: xuyingzhi1995@163.com
}

How to cite this paper: Xue, C., \& Xu, Y. Z. (2017). On the Origin of Early Jade Dagger-Axe: A Brief Analysis. Archaeological Discovery, 5, 178-186.

https://doi.org/10.4236/ad.2017.53011

Received: June 20, 2017

Accepted: July 23, 2017

Published: July 28, 2017

Copyright (c) 2017 by authors and Scientific Research Publishing Inc. This work is licensed under the Creative Commons Attribution International License (CC BY 4.0).

http://creativecommons.org/licenses/by/4.0/

\begin{abstract}
The jade dagger-axe is a significant ritual artifact in prehistoric China and therefore has been the subject of much discussion among archaeologists and historians. The authors compare the jade dagger-axe and the axe in terms of the morphological features, the means of hafting, and the use in burial ritual. It appears that the shape of the jade dagger-axe is the result of improving the axe. The means of hafting the jade dagger-axe is generally identical to that of the axe. The ritualization of the jade dagger-axe follows that of the axe. Therefore, the jade dagger-axe may have originated from the axe.
\end{abstract}

\section{Keywords}

Jade Dagger-Axe, Axe, Morphological Feature, Tying Means, Burial Ritual

\section{Introduction}

The dagger-axe has played a unique role in Chinese history as a weapon of war in the late Neolithic as well as during the Xia and Shang Dynasties. For the most part, the early dagger-axe is comprised of a haft (na), a ridge (yuan), and edge (feng), while the ancillary blade $(h u) \mathrm{u}$ and a hole for hafting appear later (Figure 1). The jade dagger-axe is a non-utilitarian tool, which first appeared in the middle and late Neolithic, and is therefore the oldest jade weapon type; it is also the most common jade artifact, has the longest period of use, as well as the most obvious ritual function.

\section{History of Morphological Change in Jade Dagger-Axes}

The earliest Neolithic jade dagger-axe dating to 5600 B.C. was discovered in the Lingjiatansite, Hanshan, Anhui. In 1998, during the third excavation of the Lingjiatan site, a jade dagger-axe was unearthed in burial M29. This axe was fa- 


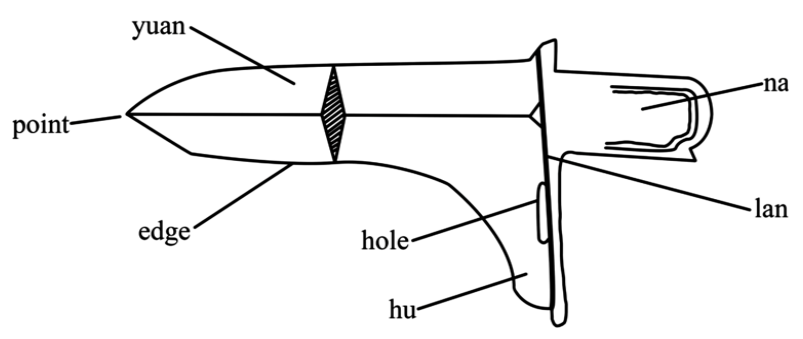

Figure 1. Construction of the dagger-axe.

shioned from a gray-yellow jade with red dots, and had a hole drilled on both blade. The blunt edge was symbolically made, so it may refer to a ritualized character (Anhui Provincial Institute of Cultural Relics and Archaeology, 1999). The jade dagger-axe became a common item in noble burials during Erlitou Culture III, and this practice became institutionalized during the late Shang Dynasty. In the Eastern Zhou Dynasty, the status of jade weapons dropped markedly. However, the dagger-axes of that period were still frequently seen in burials. Due to the geographic limit of jade, jade dagger-axes do not include the type with qiong hafting, so they are divided into straight and curved blade types. The straight yuan type is more common.

The evolution of the jade dagger-axe is clear (Figure 2).

During the Erlitou culture, the jade dagger-axe type is featured by narrow and long blades, straight haft, and is more detailed. The jade dagger-axe of this period became larger size, some attained a length of more than $40 \mathrm{~cm}$. Such size reveals their purpose to be a declaration of the owner's power. The jade daggeraxe found in Erlitou III burial M1 has a slightly curved blade, both of the edges unified to be a point, no hilt (lan), narrow and short haft with a distinct border to the blade, and a round hole drilled from one side. There is a blue-black line on the lan of yuan and na, which may have been drawn in the process of making na (Cheng, 2003).

On the other hand, the gray jade dagger-axe unearthed in Erlitou III burial M3 has a straight ridge that comes to a sharp point, thinness of edge, double na, a hole drilled from one side of the haft, five groups of incised parallel thin lines which are straight and regular, extremely carefully polished (Song, 2010). The jade dagger-axe unearthed in one Erlitou IV burial is double edged, with a triangle blade head, parallel incised lines, little ears, and a round hole on the blade.

As the capital city of Shang Dynasty, Zhengzhou Shang is an important component of Shang culture. The shape of the jade dagger-axes from Zhengzhou Shang city is quite similar to those found at the Erlitou Site. However, they have straight hafts and long blades, a hole on the blade, double-edged, a middle ridge, a general length of $20-50 \mathrm{~cm}$, revealing that the jade dagger-axes are generally larger in Early Shang dynasty. A relatively complete jade dagger-axe unearthed from lower Erligang II is large and complicated, thus, it is representative. The end of the haft is missing. The yuan is oblique and straight, pointed in the front, thinness of edge with a middle ridge. The haft is narrow in front and wide in rear, with two round holes on the margin and end. There are several scratches 


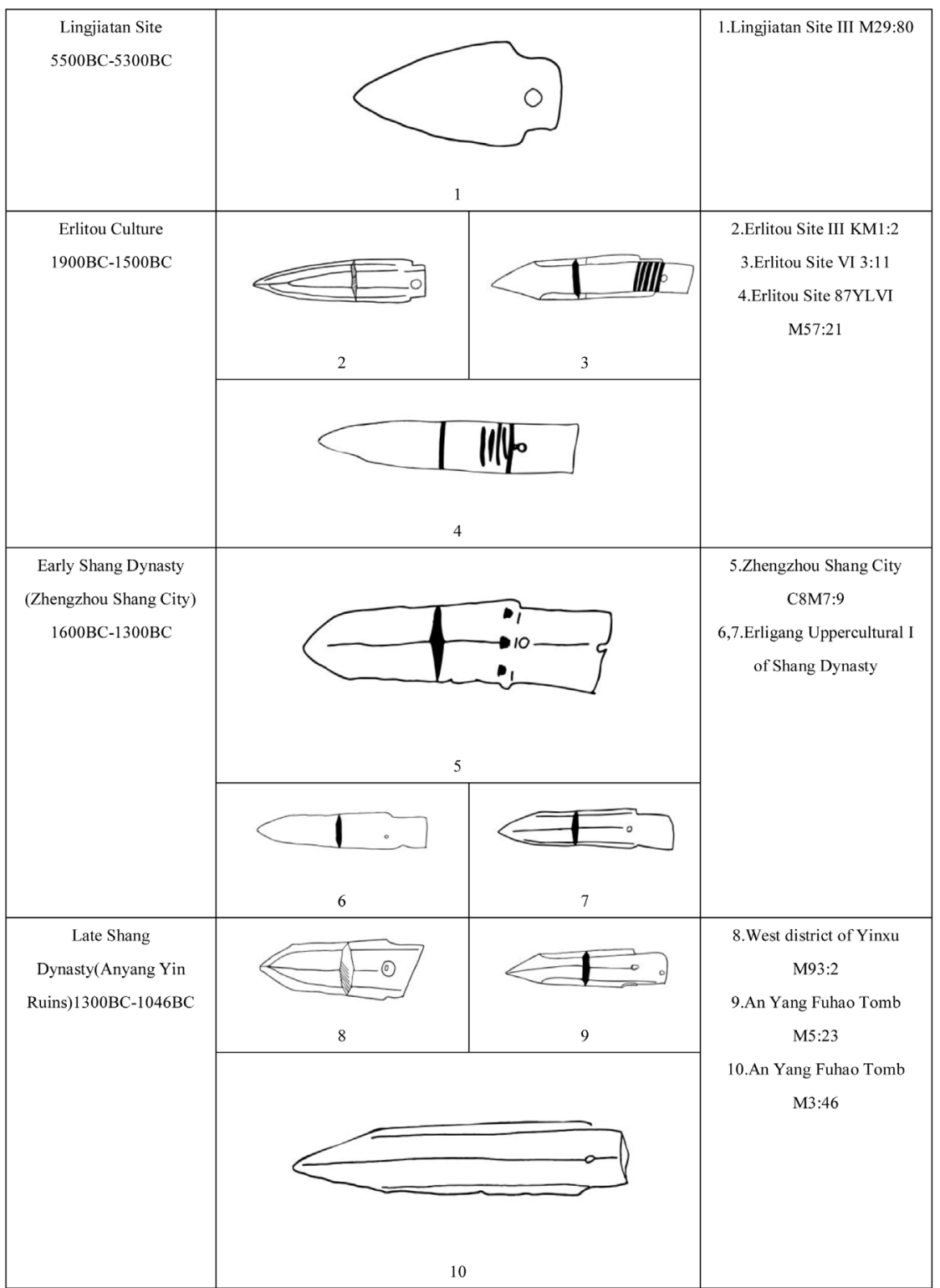

Figure 2. The evolution of the jade dagger-axe.

on the end of blade, near to the hilt (Song, 2004).

More than 170 jade dagger-axes of late Shang dynasty have been unearthed; most of these are from Anyang Yin Ruins. Thirty-nine were buried as funeral objects in the famous Fuhao Tomb. The gray jade in the Fuhao Tomb has a sharp front point. It has a blade with one side flat and straight while another side is slightly oblique. Circle designs are curved on upper and under near the hilt, which is rare in Shang Dynasty, and a straight haft with a round hole on the front. Another dagger-axe has a bronze haft and a jade blade. It was found in a burial that has a jade tablet shaped blade with sharp front edges, double edges, and a hole near to the end of the na. The bronze haft is bird shaped, curved, with a complex design (Song, 2004).

The developing trend of Yin Ruins jade dagger-axes is bifurcated. Part of them 
inherited characteristics of Early Shang Dynasty dagger-axes and are rigorously designed figures, with sharp edges, strong ridge lines, and careful manufacture. These mainly appear in noble burials that suggest high status. The others gradually became smaller and more symmetrical, and are found in small burials of people who were in the lower hierarchy of the Yin Ruins in large number.

\section{The Morphological Sequence between Jade Dagger-Axe and the Axe}

There is no explicit explanation concerning the interrelationship between fu (a kind of weapon in ancient China) and yue (a battle-axe used in ancient China), but it is sure that yue has played a leading role in the developing process, so we mainly analyze the evolving sequence involving jade dagger-axe and axe using classification of stone fu. There are two general groups of prehistoric fu, one of which is thick and strong, coarsely manufactured, with a similar elliptic profile and no holes, another is relatively thin and sharp, relatively complexly made, oblong fracture surface, with holes or shoulders (Qian, 2009). Some Chinese archaeologists believe the thick type was made for woodcutting, and should not be used in combat because it has no holes, showing that the head was not held tightly to the handle. The other type is thin and with holes, and is believed to be for combat. It is not clear about the specific distinction between $f u$ and yue, so there is no clear distinction drawn in the classification. Therefore, this essay refers to some Chinese archaeologists in terms of classifying weapon axes (Figure 3).

The axe in Peiligang is irregular in shape, with blunt edges and no holes. It became relatively regular in shape in Yangshao culture, with sharp edges, and hafting holes. The axe in Longshan culture is regular in shape, sharp and symmetrical, with holes. Axes of Xia, Shang and Zhou Dynasties are sharp, symmetrical, with holes. Their shapes are mostly rectangular. The axes in this period are elaborate and of decent quality material. The basic trend is that the axe develops from being irregularly shaped in early stage to a clear shape in the late stage, from no holes to holes for hafting, from blunt-edged to sharp-edged. This shows that the morphology of axes gradually becomes similar to that of jade dagger-axes after contemporary Yangshao culture, especially in Longshan period to Xia, Shang, and Zhou dynasties. The axe gradually becomes narrow and long, sharp-edged, with parallel sides; this makes it very similar to contemporary jade dagger-axes. As shown in the figure, the earliest jade dagger-axe discovered in the Lingjiatan site is similar to the basic morphology of the axe after contemporary Yangshao culture, and the two tend to converge in the late period. Therefore, based on the morphological change, it appears that the emergence and development of the jade dagger-axe was affected by the axe.

\section{The Similarity in Jade Dagger-Axe and Axe Hafting}

The function of the axe is irreplaceable in human society from the origin of humans to the historical period, and it is generally agreed how axes were hafted. 


\begin{tabular}{|c|c|c|c|c|}
\hline & Common Fu & Xie Shaped Fu & Yue Shaped Fu & Note \\
\hline $\begin{array}{c}\text { Type I } \\
\text { Peiligang } \\
\text { Culture } \\
\text { 5600BC-4000BC }\end{array}$ & 1 & 2 & 3 & $\begin{array}{c}\text { 1,2.Shawoli Site } \\
\text { (M6:1,M16:1) } \\
\text { 3.Peiligang Site } \\
\text { (M4:5) }\end{array}$ \\
\hline $\begin{array}{c}\text { Type II } \\
\text { Yangshao } \\
\text { Culture } \\
\text { 5000BC-3000BC }\end{array}$ & 4 & 5 & $\int^{1}$ & $\begin{array}{c}\text { 4.Jiangzhai } \\
\text { Site(ZHT8M170:5) } \\
\text { 5,6.Longgangsi Site } \\
\text { (M304:1,ZHT14H6 } \\
\text { 2:3) }\end{array}$ \\
\hline $\begin{array}{c}\text { Type III } \\
\text { Longshan } \\
\text { Culture } \\
\text { 2500BC-2000BC }\end{array}$ & 7 & 8 & 9 & $\begin{array}{c}\text { 7,9. Wangchenggan } \\
\text { g Site } \\
\text { (WT259H705:2,W } \\
\text { T96H210:2) } \\
\text { 8.Taosi Site } \\
\text { (Human Bones } \\
\text { And fus in M13:64) }\end{array}$ \\
\hline $\begin{array}{c}\text { Type IV } \\
\text { Xia } \\
\text { 2070BC-1600BC } \\
\text { Shang } \\
\text { 1600BC-1046BC } \\
\text { Zhou } \\
\text { 1046BC-249BC } \\
\text { Dynasties }\end{array}$ & 10 & 11 & 12 & $\begin{array}{c}\text { 10.Cemetery of Bo } \\
\text { hierachy(BRMl } \\
\text { II:52) } \\
\text { 11.Erlitou } \\
\text { Site(K3:81) } \\
\text { 12.Qijia } \\
\text { Site(M19:31) }\end{array}$ \\
\hline
\end{tabular}

Figure 3. Classification of weapon axes.

There is not a distinct border between fu and yue in prehistory. The morphological differences become gradually more obvious until the emergence of bronze yue in Xia, Shang and Zhou Dynasties. The prehistoric axe has two functions, one of which is practical and the other is ritual. During the early period of the axe's development, the axe was limited to practical use in situations like wood-cutting and combat; the ritual use comes gradually into sight later, after a certain level of hierarchy is reached. In the early period, the axe is used to cut trees and work other materials, and handles were attached under hunting and combat circumstances in order to improve safety.

In the Paleolithic age, the manufacture of an axe consists primarily of tying a wooden handle onto the stone axe head. It is usually cross-tied to increase stability (Zhang, 2011). In Neolithic age, after lithic technology had improved markedly, most lithic tools were fastened more securely to their handles, so the effectiveness of the tools was improved. 
There has been a long debate on the how stone axes were fixed to their handles, mostly because the handle is rarely preserved. However, a stone Fu with a wooden handle, unearthed in a Liangzhu cultural site, assists in understanding how these stone axe heads were hafted. This stone axe head was cylinder, flat topped, and the top face is slightly smaller than the body. The surface was not polished except for the edge. The stone fu was hafted onto a round, straight wooden handle, is thick on the distal end, and thin at the proximal end, orgrip. The hafting method was to thrust the head of the fu into the mortise of the wooden handle. This tool used solely the wedge and mortise method, thus the name, "wedge and mortise." Stone axes in the Neolithic age are generally trapezoid, rectangular, ellipse. They also share a common tapering feature: the proximal end of the axe is likely to be narrow, and the general shape is regular. The tapering of the axe head is so that it can be fit into the mortise joint of the handle (Xiao, 1982). A similar stone axe with a wooden handle and a "wedge and mortise" hafting feature was unearthed in a well of the Liangzhou culture by the Nanjing Museum and Cultural Institute of Wu County.

The hafting method is the same between stone $f u$ and holes. The difference here is that the handle was thrust onto the stone $f u$, which was then tied to the handle with cord (Figure 4). A pottery model of a stone fu with a hole and a handle was discovered in 1979 during excavation of Qingdun, the Liangzhu cultural site, Hnian County, Jiangsu province (Xiao, 1982). This ceramic model indicates that the axe in a simple wedge and mortise hafting mode may become eventually loose, so it is necessary to overcome this shortcoming by ropes. Of course, there are other means to fix an axe head to a handle other than wedge and mortise, but that was the most popular means in the prehistoric period. The situation should be same for stone yue, because yue is derived from fu. For example, every burial except for M12 in the south row of Yuhang site, the Liang zhu cultural cemetery, Zhejiang province. These yues are placed on the right side of the corpse, so the individuals were probably right handed.

It was pointed out that, from the first excavation of a jade dagger-axe, that its hafting means is "horizontal na and bi" (Yang, 2004). As the excavator of Erlitou site points out, the jade dagger-axe VIKM3:11 has between its blade and the upper handle "a group of parallel and shallowly carved thin lines, as well as traces of bi" (Institute of Archaeology, Chinese Academy of Social Sciences, 1965). The parallel lines are where the $\mathrm{Bi}$ (shaft) was, so they provide a rough surface to increase friction, making it more stable. Most hafting means of bi in this period is "crack split." Some jade dagger-axes have holes to increase the stability with cords fastening the parts through the holes (Shen, 1992). This method of hafting also uses the wedge and mortise method, but the hafting is improved from the previous period.

\section{The Ritual Relationship between Jade Dagger-Axe and Axe}

Axe hierarchy is present in Chinese prehistoric archaeology. This hierarchy is actually the reflection of a social phenomenon, namely the ritualization of the 


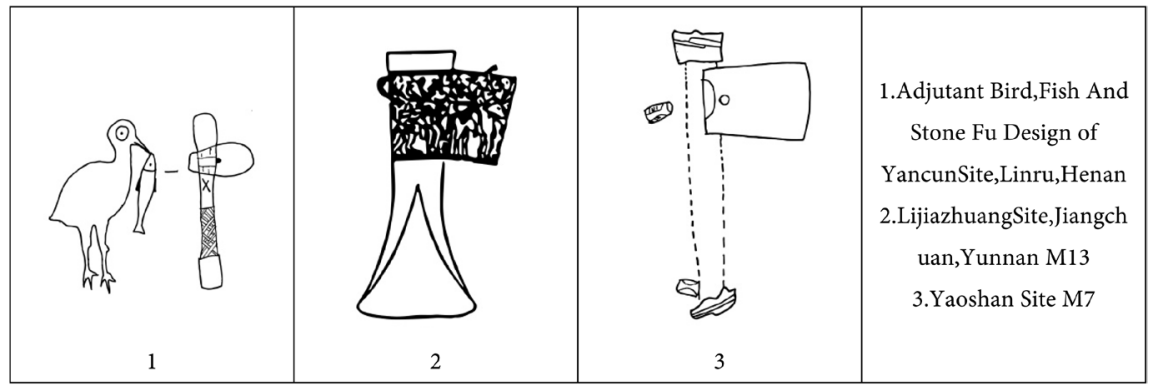

Figure 4. Hafting method of $f u$.

axe. The ritualization of the axe bears a crucial meaning in Chinese culture.

The ritualization of the axe emerged before Longshan culture, and the embodiment of it is a funeral axe. The funeral axes in burials are common in Dawenkou culture; for example, 17 of 145 (11.7\%) early Dawenkou cultural burials in Liulin site, Pei county Jiangsu province have. (Nanjing Museum, 1965). The funeral axes are found more frequently in middle and late Dawenkou cultural burials. Twenty-nine of 133 (21.8\%) were found with axes, and six of eight higher status burials include funeral axes (Institute of Archaeology, Chinese Academy of Social Sciences, 1964). Most of the axes are placed beside the left hand of the dead, and the edges are outwards, a placement that may be taken to symbolize power. These axes are generally small, finely-made, and damage is rarely seen on the edges. A fu shaped stone artifact was also found at the Xiaoshan site, Aohanqi, Inner Mongolia (called a curricular cutting elongated stone $f u$ by the excavation report) (Institute of Archaeology, Chinese Academy of Social Sciences, 1987). Its shape is the same with a stone fu, but the edge is thick and blunt, without marks of use, and an image of a human head on the top of the fu. This is viewed as a scepter held up highly in the owner's grip by the excavators (Institute of Archaeology, Chinese Academy of Social Sciences, 1987). Similar findings are found in south China, too. For example, two stone fus are found in burials M58, M44 of the Xuejiagang site, which are refined and curved with decorative patterns. These kind of stone $f u$ are made very carefully and are not likely to be used for practical uses, but as ritual objects (Anhui Provincial Institute of Cultural Relics and Archaeology, 1982).

Ritual objects are generally made carefully of specific, often of hard-to-obtain raw materials. Their surfaces should be free of marks of use, and some are decorated with patterns. A coffin for an adult unearthed in Yancun site, Linru, Henan province was decorated with an "adjutant bird, fish and stone fü" (The Museum of Liru, 1981). The stone fu is drawn with care, so it should not be a tool in practical use, but an object showing social information about the owner. A complicated stone $f u$,unearthed in the large house F2 of Zhaobaogou cultural Xiaoshan site, Aohanqi, Inner Mangolia, is polished out of a piece of glossy stone with fine stripes, and a drawing of a human face is on the top of the fu (Institute of Archaeology, Chinese Academy of Social Sciences, 1987).

This kind of stone $f u$ is a representation of a ritualized rather than a functional 
stone $f u$, and it, too, shows the social position of the individual buried in the grave. According to the funeral axes in middle and late Neolithic burials, Qian Yaopeng believes that the axe becomes established and prevailing as the symbol of authoritative power (Qian, 2009).

The phenomenon of funeral axes grows in number and becomes common during the Neolithic age. This process transfers the function of the axe, and is evidence of the emergence of hierarchy and the gap between rich and poor. The ritualization of the axe undoubtedly promotes the development of the axe's morphology, which can be in refined texture, more regular shapes and more complicated decorative patterns.

Based on the above, what are the influences on the jade dagger-axe by the ritualization of the axe? It has been mentioned previously that the ritual function of axe came into being between the middle to late period of the Neolithic, and the earliest discovered jade dagger-axe is a ritualized one, so the ritualization of jade dagger-axes has inherited that of the axe over time. The idea that a jade dagger-axe can symbolize power and status because jade is rare was formed after the axe was already ritualized. What is more, the fact that the ritualized axe was more refined in design has a strong influence on the jade dagger-axe. Except for the earliest few, jade dagger-axes are delicately produced. This phenomenon results from the demand for funeral ritual axes, since the jade dagger-axe itself is part of the ritual. The jade dagger-axe has been elaborated continuously after contemporary Erlitou culture, while the tradition to bury axes in burials has been popular through Xia, Shang and Zhou Dynasties, and jade yues as well as bronze yues are most popular in Xia, Shang and Zhou dynasties (Qian, 2009). The fact that patterns become similarity on jade yue and bronze yue in this period has an implicit influence on the jade dagger-axe, which has the same ritual meaning.

\section{Conclusion}

Strong relationships can be seen in morphological characteristics, hafting and ritualization between jade dagger-axes and axes, referring to the comparison study on the axe and the jade dagger-axe. Meanwhile, the occurrence of the axe is earlier than the jade dagger-axe, and the function of jade dagger-axe is inherited from the axe. The morphological features, function, and multiple features of axe are seen in jade dagger-axes. Therefore, the jade dagger-axe may be a derivative product specially intended to be sacrificed as part of high status burials while the early jade dagger-axe should be derived from the axe.

\section{Acknowledgements}

We would like to express our gratitude to the Cultural Heritage Department of the Northwest University, especially Professor Qingbo Duan for his advises. We are also great thankful to the Department of Anthropology of University of Wyoming, especially Professor Robert L. Kelly for his generous help. 


\section{Funding}

This article is sponsored by China Scholarship Council.

\section{Competing Interests}

The author has no competing interests to declare.

\section{References}

Anhui Provincial Institute of Cultural Relics and Archaeology (1999). The Third Excavation Report of Linjia Mountain Site in Anhui. Archaeology, 11, 56.

Anhui Provincial Institute of Cultural Relics and Archaeology (1982). The Neolithic Site of Xue Jiagang. Acta Archaeologica Sinica, 3, 35.

Cheng, X. (2003). The Unearthed Jade Analysis of Erlitou Site Tombs. Cultural Relics of Central China, 3, 23-36.

Institute of Archaeology, Chinese Academy of Social Sciences (1965). The Excavation Report of Yanshi Erlitou Site of Henan. Archaeology, 5, 250.

Institute of Archaeology, Chinese Academy of Social Sciences (1964). The First Excavation Report of Xixia Monarch Site in Qufu of Shandong. Acta Archaeologica Sinica, 2, 365.

Institute of Archaeology, Chinese Academy of Social Sciences (1987). The Xiaoshan Site of Aohan in Inner Mongolia. Archaeology, 5, 162.

Nanjing Museum (1965). The Second Excavation of Neolithic in Liulin of Jiangsu. Acta Archaeologica Sinica, 3, 165.

Qian, Y. (2009). A Preliminary Study of the Battle-Axes Using Institution in Ancient China. Acta Archaeology Sinica, 1, 7.

Shen, R. (1992). The Discussion about the Use of Early Bronze Dagger-Axe. Archaeology, 1, 54-69.

Song, A. (2004). The Unearthed Jade Analysis of Shang City of Zhenzhou. Cultural Relics of Central China, 5, 48.

Song, X. (2010). The Origin and Development of Yu Ge Evolution. Collection World, 102, 47-49.

The Museum of Liru (1981). The Research of the Neolith Site in Yan Village. Cultural Relics of Central China, 1, 62.

Xiao, M. (1982). The Discussion about Stone Froe's Handle and Using. Agricultural Archaeology, 2, 109-113.

Yang, B. (2004). The Authentication and Research about Excavated Jade. Cultural Relics of Central China, 2, 54-58.

Zhang, H. (2011). The Introduction of China Prehistorical Archaeology (p. 365). Beijing: Science Press Ltd. 
Submit or recommend next manuscript to SCIRP and we will provide best service for you:

Accepting pre-submission inquiries through Email, Facebook, LinkedIn, Twitter, etc. A wide selection of journals (inclusive of 9 subjects, more than 200 journals)

Providing 24-hour high-quality service

User-friendly online submission system

Fair and swift peer-review system

Efficient typesetting and proofreading procedure

Display of the result of downloads and visits, as well as the number of cited articles Maximum dissemination of your research work

Submit your manuscript at: http://papersubmission.scirp.org/

Or contact ad@scirp.org 